Model Choice in Consumer Analysis: Taiwan, 1970-89

Jonq-Ying Lee; Mark G. Brown; James L. Seale, Jr.

American Journal of Agricultural Economics, Vol. 76, No. 3. (Aug., 1994), pp. 504-512.

Stable URL:

http://links.jstor.org/sici?sici=0002-9092\%28199408\%2976\%3A3\%3C504\%3AMCICAT\%3E2.0.CO\%3B2-G

American Journal of Agricultural Economics is currently published by American Agricultural Economics Association.

Your use of the JSTOR archive indicates your acceptance of JSTOR's Terms and Conditions of Use, available at

http://www.jstor.org/about/terms.html. JSTOR's Terms and Conditions of Use provides, in part, that unless you have obtained prior permission, you may not download an entire issue of a journal or multiple copies of articles, and you may use content in the JSTOR archive only for your personal, non-commercial use.

Please contact the publisher regarding any further use of this work. Publisher contact information may be obtained at http://www.jstor.org/journals/aaea.html.

Each copy of any part of a JSTOR transmission must contain the same copyright notice that appears on the screen or printed page of such transmission.

The JSTOR Archive is a trusted digital repository providing for long-term preservation and access to leading academic journals and scholarly literature from around the world. The Archive is supported by libraries, scholarly societies, publishers, and foundations. It is an initiative of JSTOR, a not-for-profit organization with a mission to help the scholarly community take advantage of advances in technology. For more information regarding JSTOR, please contact support@jstor.org. 


\title{
Model Choice in Consumer Analysis: Taiwan, 1970-89
}

\author{
Jonq-Ying Lee, Mark G. Brown, and James L. Seale, Jr.
}

\begin{abstract}
Expenditure data were used to study how income and prices influenced consumer demand in Taiwan during the last decade. Alternative differential demand models combining the features of the Rotterdam model and the Almost Ideal Demand System (AIDS) were tested. AIDS-type demand responses describe Taiwanese consumer behavior better than do the other specifications.
\end{abstract}

Key words: consumer demand, food demand, model choice, nonnested test.

In the last several decades, consumer demand analysis has moved toward system-wide approaches. There are now numerous algebraic specifications of demand systems, including the linear and quadratic expenditure systems, the Working model, the Rotterdam model, translog models, and the Almost Ideal Demand System (AIDS). Generally, different demand specifications have different implications. Two demand systems which have become popular in agricultural economics are the Rotterdam and the AIDS. However, the assumptions used to parameterize these two systems have different implications. For example, marginal expenditure shares and Slutsky terms are assumed constants in the Rotterdam model, while they are assumed functions of budget shares in the AIDS.

Economic theory does not provide criteria to choose ex ante between these two systems; instead, researchers often rely on statistical tests and inference. When competing demand systems are nested, statistical tests (Amemiya, p. 142) can be used to choose the model which best represents the data. However, when systems are not nested, one needs an alternative testing procedure for the competing alternatives. Deaton (1978) applied a nonnested test to

\footnotetext{
Jonq-Ying Lee and Mark G. Brown are research economists with the Florida Department of Citrus; James L. Seale, Jr. is an associate professor with the Food and Resource Economics Department, University of Florida.

Research was partially supported by the U.S. Department of Agriculture Grant No. 93-37400-9086 at the University of Florida The authors would like to thank Anton Barten for his support and helpful comments. Seniority of authorship is shared among the three authors.

Florida Agricultural Experiment Station Journal Series No. R03694.

Review coordinated by Steven Buccola.
}

compare demand systems with the same dependent variables, but his test is not applicable when comparing the Rotterdam and AIDS because they have different dependent variables. Barten (1993) demonstrated that the Rotterdam and the AIDS are special cases of, and nested within, a more general demand system, and he suggested pair-wise and higher-order tests to choose which of the competing special cases (AIDS, Rotterdam, and hybrids of the AIDS and Rotterdam) best explains the data. ${ }^{1}$ Lee, Brown, and Seale used the pair-wise test developed by Barten (1993) to choose between the Rotterdam and a hybrid of the Rotterdam and Working model. Alston and Chalfant also developed pair-wise tests for choosing between the Rotterdam and the AIDS. However, these studies did not utilize higher-order comparisons such as those developed by Barten (1993).

In the present paper, we examine how income and prices influenced Taiwanese consumer demand including food during the last two decades, and particularly how demand elasticities have evolved over time. Four versions of the differential demand system examined by Barten (1993) - the Rotterdam; a differential version of the AIDS; and two mixed models, the CBS system and $\mathrm{NBR}^{2}$ system with features of both the Rotterdam and AIDS systems-are fit to the data. A general model which nests these four is developed to help choose the model which best

\footnotetext{
1 The AIDS and Rotterdam, for example, are not directly tested against each other, but against the more general demand system within which both are nested.

${ }^{2}$ The models are named after the Netherlands Central Bureau of Statistics and the National Bureau of Research, where Keller, van Driel and Neves worked when the respective models were developed.
} 
fits the data. Finally, we discuss the behavior of Taiwanese demand elasticities over time.

\section{The Differential Approach}

The Rotterdam model, due to Barten (1964) and Theil (1965), takes the form (with time subscripts omitted for convenience)

$$
\text { (1) } \begin{aligned}
w_{i} d \log q_{i} & =\theta_{i} d \log Q \\
& +\sum_{j} \pi_{i j} d \log p_{j} i=1,2, \ldots, n
\end{aligned}
$$

where $w_{i}$ represents the average budget share of commodity $i ; p_{i}$ and $q_{i}$ are the price and quantity of good $i$, respectively; $d \log p_{i}$ and $d \log q_{i}$ represent $d p_{i} / p_{i}$ and $d q_{i} / q_{i}$, respectively; and $d \log Q$ is an index number (Divisia volume index) for the change in real income

$$
d \log Q=\sum_{i} w_{i} d \log q_{i}
$$

Demand parameters $\theta_{i}$ and $\pi_{i j}$ are given by

$$
\text { (3) } \begin{aligned}
\theta_{i} & =p_{i}\left(\partial q_{i} / \partial m\right), \quad \pi_{i j}=\left(p_{i} p_{j} / m\right) s_{i j}, \\
s_{i j} & =\partial q_{i} / \partial p_{j}+q_{j} \partial q_{i} / \partial m
\end{aligned}
$$

where $m$ is total outlay or the budget and $s_{i j}$ is the $(i, j)$ th element of the Slutsky substitution matrix, parameter $\theta_{i}$ is the marginal budget share of commodity $i$, and $\pi_{i j}$ is a compensated price effect. The constraints of demand theory can be directly applied to the Rotterdam parameters. In particular, we have

$$
\begin{array}{ll}
\text { (4) Adding-up } & \sum_{i} \theta_{i}=1, \sum_{i} \pi_{i j}=0 \\
\text { (5) Homogeneity } & \sum_{j} \pi_{i j}=0, \text { and } \\
\text { (6) Slutsky Symmetry } & \pi_{i j}=\pi_{j i} .
\end{array}
$$

The Rotterdam is a particular parameterization of a system of differential demand equations, where demand parameters $\theta_{i}$ 's and $\pi_{i j}$ 's are assumed to be constant. However, there is no strong a priori reason that the $\theta_{i}$ 's and $\pi_{i j}$ 's should be held constant. An alternative parameterization is based on the Working model

$$
\text { (7) } w_{i}=\alpha_{i}+\beta_{i} \log m, \quad i=1,2, \ldots, n \text {. }
$$

As the sum of the budget shares is unity, it follows from (7) that $\sum \alpha_{i}=1$ and $\sum \beta_{i}=0$. To de- rive the marginal shares implied by the Working model, one multiplies (7) by $m$ and differentiates with respect to $m$,

$$
\begin{aligned}
\partial\left(p_{i} q_{i}\right) / \partial m & =\alpha_{i}+\beta_{i}(1+\log m) \\
& =w_{i}+\beta_{i}
\end{aligned}
$$

Hence, under this formulation the $i$ th marginal share differs from the corresponding budget share by $\beta_{i}$. The budget share is not constant with respect to income, and neither is the associated marginal share.

The income elasticity corresponding to (8) is

$$
\eta_{i}=1+\beta_{i} / w_{i}
$$

This expression indicates that a good with positive (negative) $\beta_{i}$ is a luxury (necessity). Since the budget share of a luxury increases with income (prices remaining constant), it follows from (9) that increasing income causes the $\eta_{i}$ for such a good to fall toward one and as the consumer becomes more affluent, luxury goods become less luxurious, a plausible outcome. The income elasticity of a necessity also declines with increasing income under (9) and, if $\beta_{i}=0$, the good is unitary elastic and the budget share will not change in response to income changes (again, prices held constant).

Replacing $\theta_{i}$ in (1) with (8) and rearranging terms, one obtains

$$
\begin{aligned}
w_{i} d \log q_{i} & =\left(\beta_{i}+w_{i}\right) d \log Q \\
& +\sum_{j} \pi_{i j} d \log p_{j}
\end{aligned}
$$

where $\beta_{i}$ and $\pi_{i j}$ are constant coefficients (Keller and van Driel; Theil and Clements). Equation (10) is referred to as the CBS, following Keller and van Driel.

The AIDS has the same intercept and income term as equation (7) but also includes price effects and is specified as

$$
w_{i}=\alpha_{i}+\sum_{j} \gamma_{i j} \log p_{j}+\beta_{i} \log (m / P)
$$

where $P$ is a price index defined by

$$
\begin{aligned}
\log P & =\alpha_{0}+\sum \alpha_{k} \log p_{k} \\
& +1 / 2 \sum_{k} \sum_{l} \gamma_{k l} \log p_{k} \log p_{l}
\end{aligned}
$$

The adding-up restriction requires that $\sum_{i} \alpha_{i}=1$, $\sum_{i} \beta_{i}=0, \sum_{i} \gamma_{i j}=0$; homogeneity is satisfied if and only if $\sum_{i} \gamma_{j i}=0$; and symmetry is satisfied 
provided that $\gamma_{i j}=\gamma_{j i}$.

The differential form of equation (11), based on Deaton and Muellbauer's suggestion of substituting the Divisia Price index $\sum w_{i} d \log p_{i}$ for $d \log P$ [the differential form of equation (12)], ${ }^{3}$ is

$$
d w_{i}=\beta_{i} d \log Q+\sum_{j} \gamma_{i j} d \log p_{j}
$$

or

$$
\begin{aligned}
w_{i} d \log q_{i} & =\left(\beta_{i}+w_{i}\right) d \log Q \\
& +\sum_{j}\left[\gamma_{i j}-w_{i}\left(\delta_{i j}-w_{j}\right)\right] d \log p_{j}
\end{aligned}
$$

where $\delta_{i j}$ is the Kronecker delta equal to unity if $i=j$ and zero otherwise [Barten (1993)]. To derive (13a) from (13), use the relations $d w_{i}=$ $w_{i}\left(d \log p_{i}+d \log q_{i}-d \log m\right)$ and $d \log m=d \log P$ $+d \log Q$. Further,

$$
\begin{aligned}
& \beta_{i}=\theta_{i}-w_{i} \text { and } \\
& \gamma_{i j}=\pi_{i j}+w_{i} \delta_{i j}-w_{i} w_{j} .
\end{aligned}
$$

A fourth alternative, the NBR (Neves), can be derived by substituting $\theta_{i}-w_{i}$ for $\beta_{i}$ in (13) so that it has the Rotterdam income coefficients but the AIDS price coefficients. Specifically, the NBR is

$$
\begin{aligned}
d w_{i} & +w_{i} d \log Q \\
& =\theta_{i} d \log Q+\sum_{j} \gamma_{i j} d \log p_{j}
\end{aligned}
$$

Similarly, equation (15) can be rewritten as

$$
\begin{aligned}
w_{i} d \log q_{i} & =\theta_{i} d \log Q \\
& +\sum_{j}\left[\gamma_{i j}-w_{i}\left(\delta_{i j}-w_{j}\right)\right] d \log p_{j} .
\end{aligned}
$$

The four models [equations (1), (10), (13a), and (15a)] have the same left-hand side variable $w_{i} d \log q_{i}$ and right-hand side variables $d \log Q$ and $d \log p_{j} s$. These models can be considered as four different ways to parameterize a general model; marginal budget shares are assumed to be constant (i.e., $\theta_{i}$ ) in the Rotterdam and the NBR but variable (i.e, $\beta_{i}+w_{i}$ ) in the AIDS and CBS. The Slutsky terms are considered to be constants (i.e., $\pi_{i j}$ ) in the Rotterdam and CBS and variables [i.e., $\gamma_{i j}-w_{i}\left(\delta_{i j}-w_{j}\right)$ ] in the AIDS and NBR. The CBS and the NBR can be considered as income-response variants of

\footnotetext{
${ }^{3}$ When one uses the Divisia price index for $d \log P$, equation (13) and (13a) are close approximations of the differential AIDS.
}

the Rotterdam and the AIDS, respectively.

These four models are not nested but, following Barten (1993, p. 154), a general demand system can be developed which nests all four. The general system is

$$
\begin{array}{r}
w_{i} d \log q_{i}=\left(d_{i}+\delta_{1} w_{i}\right) d \log Q \\
+\sum_{j}\left[e_{i j}-\delta_{2} w_{i}\left(\delta_{i j}-w_{j}\right)\right] d \log p_{j} \\
i=1,2, \ldots, n
\end{array}
$$

where $d_{i}=\delta_{1} \beta_{i}+\left(1-\delta_{1}\right) \theta_{i}$ and $e_{i j}=\delta_{2} \gamma_{i j}+(1-$ $\left.\delta_{2}\right) \pi_{i j} ; \delta_{1}$ and $\delta_{2}$ are two additional parameters to be estimated. Note that (16) becomes the Rotterdam when both $\delta_{1}$ and $\delta_{2}$ are restricted to zero, the CBS when $\delta_{1}=1$ and $\delta_{2}=0$, the AIDS when $\delta_{1}=1$ and $\delta_{2}=1$, and the NBR when $\delta_{1}=$ 0 and $\delta_{2}=1$. The demand restrictions on (16) are

$$
\begin{array}{ll}
\text { Adding-up } & \sum_{i} d_{i}=1-\delta_{1} \text { and } \sum_{i} e_{i j}=0 \\
\text { Homogeneity } & \sum_{j} e_{i j}=0, \text { and } \\
\text { Symmetry } \quad e_{i j}=e_{j i} .
\end{array}
$$

Because (16) with its two additional parameters nests all four, it can be used as a model selection tool. For application to discrete data, the specifications are approximated by replacing $w_{i}$ by $\left(w_{i t}+w_{i t-1}\right) / 2, d \log q_{i}$ by $\log \left(q_{i t} / q_{i t-1}\right)$, and $d \log p_{i}$ by $\log \left(p_{i t} / p_{i t-1}\right)$, where subscript $t$ indicates time.

The likelihood ratio test (LRT) for model selection is

$$
\text { (18) } \quad \text { LRT }=-2\left[\log L\left(\boldsymbol{\theta}^{*}\right)-\log L(\boldsymbol{\theta})\right]
$$

where $\boldsymbol{\theta}^{*}$ is the vector of parameter estimates of either the Rotterdam, the AIDS, or their variants; $\boldsymbol{\theta}$ is the vector of parameter estimates of the general model; and $\log L(\cdot)$ is the log value of the likelihood function (Amemiya, pp. 14146). For example, under the null hypothesis that the Rotterdam best describes the data, test statistic LRT has an asymptotic $\chi^{2}(q)$ distribution, in which $q=2$ is the number of restrictions imposed (i.e., the degrees of freedom equal to the difference between the number of parameters in the general model and in the Rotterdam).

\section{Data}

Taiwanese household data on personal consumption during the years 1970 through 1989 were analyzed. The data were collected monthly 
Table 1. Taiwanese Budget Shares and Price Indices for Seven Categories of Goods, 1970 through 1989

\begin{tabular}{lccccccc}
\hline Year & Food & Clothing & Housing & Educ. & Medical & Trans. & Misc. \\
\hline \multicolumn{7}{c}{ Budget Share } \\
1970 & 0.4375 & 0.0685 & 0.3077 & 0.0743 & 0.0346 & 0.0328 & 0.0447 \\
Average & 0.3811 & 0.0625 & 0.3246 & 0.0919 & 0.0348 & 0.0561 & 0.0490 \\
1989 & 0.2937 & 0.0746 & 0.3402 & 0.1201 & 0.0351 & 0.0782 & 0.0582 \\
\hline \multicolumn{7}{c}{ Price Index (1962-64 Average = 100) } \\
1970 & 117.53 & 121.23 & 97.07 & 118.81 & 111.80 & 129.28 & 108.92 \\
Average & 245.94 & 270.11 & 199.38 & 214.28 & 198.76 & 263.23 & 250.23 \\
1989 & 344.85 & 379.59 & 237.31 & 296.21 & 245.52 & 386.32 & 414.88 \\
\hline
\end{tabular}

Source: Directorate-General of Budget, Accounts and Statistics, Executive Yuen "Monthly Statistics of the Republic of China," Taipei, Republic of China, 1970 through 1990.

through household expenditure surveys by the City Government of Taipei (Directorate-General of Budget, Accounts and Statistics, Executive Yuen, Republic of China) based on a sample of 285 to 580 households. In the present study, monthly household average expenditures were used. Basic information on twelve commodity groups were available, but because there were no detailed price indices for all twelve commodity groups, the commodities were aggregated into seven.

1. Food: at-home and away-from-home food, beverages, and tobacco

2. Clothing and other personal effects

3. Housing and household: rent and water charges, fuel and light, furniture, furnishing and household equipment, and household operation expenses

4. Medicines and medical care

5. Transportation and communication

6. Education/entertainment

7. Miscellaneous

Table 1 shows the budget or expenditure shares of the seven commodity groups for 1970, the sample mean, and 1989. The largest average expenditure share was for food $(0.38)$ and the lowest was for medicines and medical care $(0.04)$. In general, the group budget shares were relatively constant over the sample period except for food, education and entertainment, and transportation. The expenditure share of food decreased the most from $43.8 \%$ of total expenditures in 1970 to $29.4 \%$ in 1989: the expenditure share of transportation increased the most from $3.3 \%$ to $7.8 \%$ during the same period.

Price indices are also reported in table 1. Although all indices increased from 1970 to 1989 , they increased at different rates. The miscellaneous price index almost quadrupled while
Table 2. Test Results for the Rotterdam Model, CBS, AIDS, NBR, and General Model with First-Order Autocorrelation Imposed

\begin{tabular}{lcc}
\hline Model & Log likelihoods & $-2[L(\theta *)-L(\theta)]^{\mathrm{a}}$ \\
\hline & \multicolumn{1}{c}{ Adjusted for first-order autocorrelation } \\
\cline { 2 - 3 } & & \\
General model & $451.334^{\mathrm{c}}$ & \\
Rotterdam & 358.148 & 186.372 \\
CBS & 359.349 & 183.397 \\
AIDS & $449.855^{\mathrm{c}}$ & 2.958 \\
NBR & $440.552^{\mathrm{c}}$ & 21.564 \\
\hline
\end{tabular}

The table value for $\chi_{(2)}{ }^{2}=5.99$ at $\alpha=0.05$ level.

b The estimates for $\delta_{1}$ and $\delta$ in (14) are 0.7699 and 0.9672 with standard errors 0.0616 and 0.0160 , respectively.

c First-order autocorrelation coefficient (Berndt and Savin) is at least twice as large as its asymptotic standard error.

those of food, clothing and other personal effects, and transportation and communication essentially tripled. The price index that increased the least was that of medicines and medical care.

\section{Analysis and Results}

Since the four competing systems (i.e., the Rotterdam, AIDS, CBS, NBR) and the general system automatically satisfy the adding-up conditions, only six equations were estimated for the seven-good systems (the miscellaneous equation was not included; see Barten, 1969). Homogeneity, symmetry, and first-order autocorrelation (Berndt and Savin) were imposed, and the models were estimated by the maximum likelihood method. For the AIDS, NBR, and general model, the estimated first-order autocorrelation coefficient was at least two 
Table 3. Implied Marginal Shares and Slutsky Coefficients Based on Parameter Estimates of the Autocorrelation-Corrected AIDS, Homogeneity, and Symmetry Imposed

\begin{tabular}{lcccccccc}
\hline Commodity & Marginal budget & \multicolumn{7}{c}{ Slutsky coefficient $\left(\pi_{i j}\right)$} \\
\cline { 3 - 9 } Group & share $\left(\theta_{i}\right)^{\mathrm{a}}$ & Food & Clothing & Housing & Edu. \& ent. & Med. care & Trans. & Misc. \\
\hline Food & 0.346 & -0.243 & 0.024 & 0.120 & 0.038 & 0.014 & 0.024 & 0.0227 \\
& $(0.016)^{\mathrm{b}}$ & $(0.006)$ & $(0.002)$ & $(0.003)$ & $(0.002)$ & $(0.002)$ & $(0.003)$ & $(0.006)$ \\
Clothing & 0.895 & & -0.057 & 0.021 & 0.004 & 0.002 & 0.006 & -0.000 \\
& $(0.002)$ & & $(0.006)$ & $(0.001)$ & $(0.001)$ & $(0.001)$ & $(0.001)$ & $(0.002)$ \\
Housing & 1.322 & & & -0.218 & 0.028 & 0.012 & 0.019 & 0.019 \\
& $(0.001)$ & & & $(0.009)$ & $(0.002)$ & $(0.001)$ & $(0.001)$ & $(0.001)$ \\
Education. & 0.063 & & & & -0.082 & 0.003 & 0.003 & 0.006 \\
\& entertainment & $(0.001)$ & & & & $(0.005)$ & $(0.001)$ & $(0.001)$ & $(0.001)$ \\
Medical care & 0.965 & & & & & -0.034 & 0.001 & 0.001 \\
& $(0.001)$ & & & & & $(0.006)$ & $(0.001)$ & $(0.001)$ \\
Transportation & 1.065 & & & & & & -0.054 & 0.001 \\
& $(0.001)$ & & & & & & $(0.007)$ & $(0.001)$ \\
Miscellaneous & 0.954 & & & & & & & -0.049 \\
& $(0.002)$ & & & & & & & \\
\end{tabular}

a Estimated at sample mean budget shares.

b Numbers in parentheses are asymptotic standard errors.

times greater than its asymptotic standard error. Log-likelihood values and corresponding test statistics for each of the systems are presented in table 2. Numbers in the first column of table 2 are the log-likelihoods and the numbers in the second column are the log-likelihood ratio test statistics [equation (18)] for model selection. The test results show that the general system rejects the Rotterdam, CBS, and NBR. Only the AIDS is not rejected by the general system, implying the AIDS fits the data better than do the other three. Accordingly, only results based on AIDS corrected for autocorrelation are reported and discussed further in this section.

\section{Endogeneity and Goodness of Fit}

The $d \log Q$ term and disturbance terms $\left(\varepsilon_{i} s\right)$ used in the AIDS may not be independent of each other (Theil, 1976; Attfield). In examining this potential endogeneity problem, the theory of random rational behavior (Theil 1975, 1976, 1980; Theil and Clements 1978; Duffy p. 1060) was invoked. Theil shows that if $d \log Q$ is exogenous (i.e., the disturbance term is normal with zero mean and independent of $d \log Q$ ) the disturbance covariance terms are proportional to the Slutsky terms such that $\operatorname{cov}\left(\varepsilon_{i} \varepsilon_{j}\right)=\alpha \pi_{i j}$, where $\alpha$ is a factor of proportionality. Using the AIDS disturbance covariance terms and the AIDS-implied Slutsky terms $\left[\pi_{i j}=\gamma_{i j}-w_{i}\left(\delta_{i j}\right.\right.$ $\left.-w_{j}\right)$ ] calculated at sample budget share means, a simple regression shows that $\operatorname{cov}\left(\varepsilon_{i} \varepsilon_{j}\right)=$ $-0.0015(0.0052)-0.7150(0.0643) \pi_{i j}$ with $\mathrm{R}^{2}$ $=0.87$, where the numbers in the parentheses are standard errors of estimates. The regression results, an insignificant intercept term and a significant negative slope term, suggest that $\operatorname{cov}\left(\varepsilon_{i} \varepsilon_{j}\right) s$ is proportional to the Slutsky terms. Hence, treating the disturbance term as independent of $d \log Q$ seems to be a reasonable approach for this data.

Single-equation $\mathrm{R}^{2}$ statistics are not good measures of fit for demand systems (Bewley). Therefore, the statistic suggested by Bewley, Young, and Coleman, $\mathrm{R}_{L}^{2}=1-1 /\{1+L R /[T(n$ -1)]\}, was used instead, where $T$ is the number of observations, $n$ is the number of equations in the system, and $L R$ is twice the difference between the log likelihood of the AIDS and the log likelihood of the same dependent variables regressed on the $d \log Q$ term only. ${ }^{4}$ For the autocorrelation-corrected AIDS with homogeneity and symmetry, $\mathrm{R}_{L}^{2}=0.85$, and indicates that the whole system explains $85 \%$ of the variation in allocation. ${ }^{5}$

\section{Parameter and Elasticity Estimates}

Instead of reporting the AIDS parameters, which may be difficult to interpret directly, marginal budget shares $\theta_{i} s$ and Slutsky terms $\pi_{i j} s$ were derived using equation (14), the AIDS parameter estimates, and sample budget share

\footnotetext{
${ }^{4}$ The naive AIDS model is $w d \log q_{i}=b d \log Q_{1}+e_{i}$. This model also satisfies the adding-up condition, $\sum b_{i}=1$, by construction.

${ }^{5}$ The autocorrelation coefficient estimate $\rho(=0.008$ with an asymptotic standard error of 0.002 ) for the AIDS was statistically different from zero at the $\alpha=0.01$ level.
} 
Table 4. AIDS Demand Elasticity Estimates for Seven Taiwanese Goods, 1970 to 1989

\begin{tabular}{|c|c|c|c|c|c|c|c|c|}
\hline \multirow[b]{2}{*}{ Commodity } & \multirow{2}{*}{$\begin{array}{l}\text { Income } \\
\text { elasticity }\end{array}$} & \multicolumn{7}{|c|}{ Compensated price elasticity } \\
\hline & & Food & Clothing & $\begin{array}{l}\text { Housing } \\
1970 \\
\end{array}$ & Edu. \& ent. & Med. care & Trans. & Misc \\
\hline Food & 0.969 & -0.578 & 0.069 & 0.002 & 0.012 & 0.008 & 0.013 & 0.054 \\
\hline Clothing & 0.895 & & -0.908 & 0.320 & 0.053 & 0.037 & 0.062 & -0.005 \\
\hline Housing & 0.963 & & & -0.689 & 0.068 & 0.038 & 0.036 & 0.053 \\
\hline $\begin{array}{l}\text { Education } \\
\quad \& \text { entertainment }\end{array}$ & 1.158 & & & & -0.905 & 0.030 & 0.000 & 0.069 \\
\hline Medical care & 1.194 & & & & & -0.985 & 0.018 & 0.028 \\
\hline Transportation & 1.112 & & & & & & -0.984 & -0.015 \\
\hline Misc. & 1.222 & & & & & & & -1.009 \\
\hline \multicolumn{9}{|c|}{ Sample Mean } \\
\hline Food & 0.965 & -0.636 & 0.063 & 0.314 & 0.099 & 0.038 & 0.063 & 0.059 \\
\hline Clothing & 0.884 & & -0.912 & 0.338 & 0.069 & 0.038 & 0.088 & -0.006 \\
\hline Housing & 0.965 & & & -0.673 & 0.086 & 0.037 & 0.059 & 0.057 \\
\hline $\begin{array}{l}\text { Education } \\
\quad \& \text { entertainment }\end{array}$ & 1.128 & & & & -0.891 & 0.031 & 0.030 & 0.068 \\
\hline Medical care & 1.193 & & & & & -0.985 & 0.041 & 0.032 \\
\hline Transportation & 1.065 & & & & & & -0.954 & 0.014 \\
\hline Misc. & 1.202 & & & & & & & -0.999 \\
\hline \multicolumn{9}{|c|}{1989} \\
\hline Food & 0.954 & -0.729 & 0.075 & 0.327 & 0.130 & 0.039 & 0.087 & 0.072 \\
\hline Clothing & 0.903 & & -0.904 & 0.351 & 0.101 & 0.037 & 0.105 & 0.013 \\
\hline Housing & 0.967 & & & -0.657 & 0.114 & 0.038 & 0.081 & 0.066 \\
\hline $\begin{array}{l}\text { Education } \\
\quad \& \text { entertainment }\end{array}$ & 1.098 & & & & -0.867 & 0.117 & 0.015 & 0.073 \\
\hline Medical care & 1.191 & & & & & -0.985 & 0.063 & 0.042 \\
\hline Transportation & 1.047 & & & & & & -0.929 & 0.033 \\
\hline Misc. & 1.170 & & & & & & & -0.983 \\
\hline
\end{tabular}

means (see table 3). Of the thirty-five estimated marginal budget shares and Slutsky terms, only four cross-price Slutsky estimates are statistically the same as zero at $\alpha=0.05$. All seven own-price Slutsky terms are negative and significantly different from zero, ranging from 0.034 for medical services to -0.243 for food. The seven marginal shares are positive and significantly different from zero, ranging from 0.346 for food to 1.322 for housing and household.

The income elasticity of each commodity group $\left(\eta_{i}\right)$ and the compensated price elasticities $\left(\eta_{i j}\right)$ are (Barten, 1993)

$$
\begin{aligned}
& \text { Income Elasticity: } \\
& \eta_{i}=\theta_{i} / w_{i} \text { or } \eta_{i}=\beta_{i} / w_{i}+1
\end{aligned}
$$

\footnotetext{
${ }^{6}$ For alternative formulas, see Green and Alston (1990 and 1991).
}

Compensated Price Elasticity:

$$
\eta_{i j}=\pi_{i j} / w_{i} \text { or } \eta_{i j}=\gamma_{i j} / w_{i}-\delta_{i j}+w_{j} \text {. }
$$

Note that in (19) both income and price elasticities are functions of budget shares. Income and price elasticity estimates of the AIDS calculated at sample budget share means and 1970 and 1989 budget shares are presented in table 4 .

Overall, changes in income elasticities were small. Most decreased slightly from 1970 through 1989; those of the clothing and housing groups increased slightly. Own-price elasticity estimates indicate the demands for all commodity groups became less sensitive to price, except for the food group, which became more price sensitive.

The inclusion of away-from-home food expenditures in the food group may help explain the relatively high income and own-price elasticity estimates, derived in this study for food. 
Table 5. Taiwanese Income and Own-Price Elasticity Estimates of Four Demand System Calculated at Sample Means and Two Selected Years

\begin{tabular}{|c|c|c|c|c|c|c|}
\hline \multirow[b]{2}{*}{ Commodity group } & \multicolumn{3}{|c|}{ Income elasticity } & \multicolumn{3}{|c|}{ Own-price elasticity } \\
\hline & 1970 & Mean & 1989 & 1970 & Mean & 1989 \\
\hline & \multicolumn{6}{|c|}{ Rotterdam } \\
\hline Food & 0.862 & 0.990 & 1.284 & -0.564 & -0.648 & -0.840 \\
\hline Clothing & 0.961 & 1.053 & 0.883 & -0.877 & -0.961 & -0.805 \\
\hline Housing & 0.993 & 0.942 & 0.898 & -0.704 & -0.668 & -0.637 \\
\hline Education \& entertainment & 1.274 & 1.029 & 0.788 & -1.098 & -0.887 & -0.679 \\
\hline Medical care & 1.325 & 1.319 & 1.306 & -0.944 & -0.940 & -0.931 \\
\hline Transportation & 1.858 & 1.085 & 0.779 & -1.519 & -0.887 & -0.637 \\
\hline \multirow[t]{2}{*}{ Miscellaneous } & 1.122 & 1.022 & 0.861 & -1.100 & -1.002 & -0.844 \\
\hline & \multicolumn{6}{|c|}{ CBS } \\
\hline Food & 0.932 & 0.921 & 0.898 & -0.568 & -0.652 & -0.846 \\
\hline Clothing & 0.968 & 0.965 & 0.971 & -0.876 & -0.960 & -0.805 \\
\hline Housing & 0.993 & 0.994 & 0.994 & -0.700 & -0.663 & -0.633 \\
\hline Education \& entertainment & 1.085 & 1.069 & 1.052 & -1.081 & -0.873 & -0.668 \\
\hline Medical care & 1.411 & 1.409 & 1.405 & -0.961 & -0.957 & -0.947 \\
\hline Transportation & 1.385 & 1.225 & 1.161 & -1.516 & -0.886 & -0.636 \\
\hline \multirow[t]{2}{*}{ Miscellaneous } & 1.024 & 1.022 & 1.018 & -1.087 & -0.991 & -0.834 \\
\hline & \multicolumn{6}{|c|}{ NBR } \\
\hline Food & 0.908 & 1.042 & 1.352 & -0.565 & -0.622 & -0.710 \\
\hline Clothing & 0.994 & 1.090 & 0.913 & -0.942 & -0.998 & -0.935 \\
\hline Housing & 0.980 & 0.929 & 0.886 & -0.692 & -0.675 & -0.660 \\
\hline Education \& entertainment & 1.210 & 0.977 & 0.748 & -0.909 & -0.894 & -0.869 \\
\hline Medical Care & 1.221 & 1.216 & 1.204 & -0.985 & -0.985 & -0.984 \\
\hline Transportation & 1.491 & 0.871 & 0.625 & -0.967 & -0.944 & -0.922 \\
\hline \multirow[t]{2}{*}{ Miscellaneous } & 1.169 & 1.066 & 0.898 & -0.970 & -0.964 & -0.953 \\
\hline & \multicolumn{6}{|c|}{ General } \\
\hline Food & 0.950 & 0.976 & 1.038 & -0.573 & -0.632 & -0.727 \\
\hline Clothing & 0.902 & 0.915 & 0.891 & -0.911 & -0.918 & -0.904 \\
\hline Housing & 0.969 & 0.959 & 0.950 & -0.690 & -0.672 & -0.656 \\
\hline Education \& entertainment & 1.190 & 1.109 & 1.030 & -0.914 & -0.893 & -0.862 \\
\hline Medical care & 1.151 & 1.149 & 1.146 & -0.966 & -0.966 & -0.966 \\
\hline Transportation & 1.220 & 1.033 & 0.959 & -0.999 & -0.950 & -0.918 \\
\hline Miscellaneous & 1.261 & 1.218 & 1.147 & -1.008 & -0.997 & -0.976 \\
\hline
\end{tabular}

Typically, food consumed at home is found to be inelastic (e.g., Theil and Clements). Food consumed away from home, which includes food purchased at restaurants, is expected to be more luxurious. The effect of increasing incomes would be to lower the share of at-home food and raise the share of more luxurious away-from-home food in the food category. Furthermore, over the last two decades, more Taiwanese women have worked outside their households, increasing the chances of spending more on away-from-home food. The combined effect of working women and increasing incomes may help explain the relatively high income and own-price elasticities for food.

\section{Functional Forms, Income, and Own-Price Elasticities}

Although income and price elasticities vary over time, demand studies frequently focus on elasticities calculated at sample means. However, some studies have examined demand parameters over time (Flood, Finke, and Theil; Seale and Theil). For example, using Japanese time series data from 1951 through 1972, Flood, Finke, and Theil show that the behavior of the income elasticity estimate for food is quite different under translog and Working models. The translog model indicates that the income elasticity for food increased from about 
0.4 to more than 0.7 over the time period studied, whereas the Working model yielded an almost equally large decline. Given that a good's income elasticity of demand is a measure of its luxury character, one might question whether the large increase in the elasticity for food implied by the translog is realistic. Elasticities implied by the Working model seem more satisfactory

To demonstrate the impact of functional form on the demand elasticities, income and ownprice elasticity estimates of the Rotterdam, CBS, and NBR are shown for years 1970, 1989, and at sample means in table 5 , and can be compared to those of the AIDS reported in table 4. Income elasticity estimates from the Rotterdam and NBR are similar in size and trend, while those from the AIDS and CBS are likewise similar. For example, over the sample period, the income elasticity estimates for food demand based on the Rotterdam and the NBR increased from about 0.9 to about 1.3 , while those based on the AIDS and CBS were always less than one and decreased slightly. These differences result from the two different types of marginal shares assumed in the systems-constant marginal shares in the Rotterdam and NBR but variable ones in the AIDS and CBScombined with a decreasing food budget share and increasing total income. Decreasing income elasticities of demand for food when income increases is consistent with economic expectations, making the findings based on the Rotterdam and NBR questionable.

Own-price elasticity estimates based on the Rotterdam and CBS are similar in size and trend while those based on the AIDS and NBR are similar. The elasticities based on Rotterdam-type price coefficients are generally larger and become more price sensitive over the sample period than those based on the AIDStype price parameters. Indeed, all own-price elasticity estimates based on the AIDS and NBR are unitary or less (in absolute values) while several estimates based on the Rotterdam and CBS are greater than unity.

The own-price elasticity estimates based on the general system are most similar to those of the AIDS for all categories of goods. Remember that the extra parameter $\delta_{2}$, which is used to test the structure of the price terms, is statistically the same as unity, which is the value of $\delta_{2}$ when the price terms follow those of the AIDS exactly. The point estimate of the general system's extra parameter $\delta_{1}$, which tests the structure of the income term, is closer to one than zero, but it is statistically different from both zero and one ( $\alpha=0.05)$, based on asymptotic t-tests. This would explain why the income elasticity estimates of the general model, though similar to those of the AIDS, lie somewhere between those based on the Workingtype income structure and the Rotterdam-type structure.

\section{Concluding Remarks}

The Rotterdam and AIDS models have been popular demand systems in empirical work. However, the functional forms of their income and price terms differ, which causes the basic demand responses for these models to differ in important ways. It is possible to develop hybrid systems of these two models which incorporate the income terms of one and price terms of the other. Choosing among the competing models can be accomplished by higher-order comparisons with a general demand system that nest the other four. Further, elasticity behaviors and other economic criteria can be used to evaluate the systems.

In our study of Taiwanese expenditure data, higher-order comparisons with the general model led to selecting the AIDS over the other systems. This result suggests that AIDS-type income and price responses better explain Taiwanese expenditure behavior than do the other models. Barten (1993) found that, with Dutch data, AIDS-type income responses and Rotterdam price responses work better than do other combinations. In addition to a demand system selection tool, the general system which combines the features of all four systems-the AIDS, CBS, NBR, and Rotterdam-can be used as a demand system in its own right with the cost of only two additional parameters.

For this particular data, the use of a Rotterdam-type income parameter gives the questionable result that food's income elasticity has increased substantially over time, exceeding unity in a number of years, while income increased and food's budget share decreased. The increase in the number of women working outside the home and the increased likelihood of away-from-home food consumption may bring a small increase in the food income elasticity, but a large increase is inconsistent with the notion of food as a necessity. The Workingtype income elasticity parameter for food decreased slightly over time, consistent with economic expectations.

[Received February 1992; final revision received February 1994.] 


\section{References}

Alston J.M., and J.A. Chalfant. "The Silence of the Lambdas: A Test of the Almost Ideal and Rotterdam Models." Amer. J. Agr. Econ. 75(May 1993):304-13.

Amemiya, T. Advanced Econometrics. Cambridge: Harvard University Press, 1985.

Attfield, C.L.F. "Homogeneity and Endogeneity in Systems of Demand Equations." J. Econ. 27(1985):197-209.

Barten, A.P. "Family Composition, Prices and Expenditure Pattern." In Econometric Analysis for National Economic Planning. P. E. Hart, G. Mills, and J.K. Whitaker, eds., London: Butterworth, 1964.

. "Maximum Likelihood Estimation of a Complete System of Demand Equations." Eur. Econ. Rev. 1(1969):7-73.

. "Consumer Allocation Models: Choice of Functional Form." Empirical Econ. 18 (1993):12958.

Berndt, E.R., and N.E. Savin. "Estimation and Hypothesis Testing in Singular Equation Systems with Autoregressive Disturbances." Econometrica 43(September-November 1975):937-56.

Bewley, R. Allocation Models: Specification, Estimation, and Applications. Cambridge MA: Ballinger Publishing Company, 1986.

Bewley, R., T. Young, and D. Coleman. "A System Approach to Modelling Supply Equations in Agriculture." J. Agr. Econ. 38(May 1987):151-66.

China, Republic of, Directorate-General of Budget, Accounts and Statistics, Executive Yuen. "Monthly Statistics of the Republic of China," Taipei, 1970 through 1990.

Deaton, A.S. "Specification and Testing in Applied Demand Analysis." Econ. J. 88(September 1978):524-36.

Deaton, A.S., and J. Muellbauer. "An Almost Ideal Demand System." Amer. Econ. Rev. 70(June 1980):312-26.

Duffy, M.H. "Advertising and the InterProduct Distribution of Demand." Eur. Econ. Rev. 31(July
1987):1051-70.

Flood, L.R., R. Finke, and H. Theil. "An Evaluation of Alternative Demand Systems by Means of Implied Income Elasticities." Econ. Letters 15(1984):21-7.

Green, R., and J.M. Alston. "Elasticities in AIDS Models." Amer. J. Agr. Econ. 72(May 1990):442-5.

"Elasticities in AIDS Models: A Clarification and Extension." Amer. J. Agr. Econ. 73(August 1991):874-5.

Keller, W.J., and J. van Driel. "Differential Consumer Demand Systems." Eur. Econ. Rev. 27(April 1985):375-90.

Lee, J., M.G. Brown, and J.L. Seale, Jr. "Demand Relationships Among Fresh Fruit and Juices in Canada." Rev. Agr. Econ. 14(July, 1992): 255-62.

Neves, P. "Analysis of Consumer Demand in Portugal, 1958-1981." Memoire de maitrise en sciences economiques, Universite Catholique de Louvain, Louvain-la-Neuve, 1987.

Seale, J.L. Jr., and H. Theil. "Income and Price Sensitivity in Demand Systems, Part I: Income Sensitivity." In Economic Models, Estimation and Socioeconomic Systems: Essays in Honor of Karl A. Fox, T.K. Kaul and J.K Sengupta, eds. Amsterdam: Elsevier Science Publishers, 1991, pp. 141-54.

Theil, H. "The Information Approach to Demand Analysis." Econometrica 33(January 1965):6787.

. "The Theory of Rational Random Behavior and Its Application to Demand Analysis." Eur. Econ. Rev. 6(July 1975):217-26.

. Theory and Measurement of Consumer Demand. New York: North-Holland, 1976.

The System-Wide Approach to Microeconomics. Chicago: University of Chicago Press, 1980.

Theil, H., and K.W. Clements. Applied Demand Analysis: Results from System-Wide Approaches. Cambridge: Ballinger Publishing Company, 1987.

Working, H. "Statistical Laws of Family Expenditure." J. Amer. Statist. Assoc. 38(March 1943):43-56. 